from $\mathrm{O}_{2}, \mathrm{O}, \mathrm{OH}$ and $\mathrm{Na}(D)$; in all these cases the peak-emitting levels occurred between 80 and $100 \mathrm{~km}$. The variations in the 5577 and $6300 \AA$. airglow emissions were discussed by F. E. Roach (U.S. National Bureau of Standards) and D. Barbier (Institut d'Astrophysique, Paris). According to the latter author, the $6300 \AA$. line from O I is the only radiation which is emitted from altitudes greatly in excess of $100 \mathrm{~km}$. Of particular interest was Barbier's recent discovery of stable red arcs emitting the $6300 \AA$. line at the low latitude of Tamanrasset (in the Sahara). The sodium twilight-glow was the subject of a paper by T. M. Donahue (Observatoire de Meudon, France). At Tamanrasset $\left(21^{\circ}\right.$ N.) thero is little seasonal variation in abundance of sodium, with about $4.5 \times 10^{9}$ atoms per cm. ${ }^{2}$ (vertical column), whereas at Haute Provence $\left(41^{\circ}\right.$ N.) the abundance varies between $2 \times 10^{9}$ and $25 \times 10^{9}$ atoms per cm. ${ }^{2}$.

Spectra of atmospheric emissions contain information about the temperature of the upper atmosphere, but difficulties in both measurement and interpretation are considerable. However, D. M. Hunten (University of Saskatchewan) demonstrated that a temperature profile between 70 and $250 \mathrm{~km}$. can be satisfactorily constructed, using rotational tempera. tures from $\mathrm{N}_{2}{ }^{+}$negative bands in auroræ and Doppler widths of forbidden lines in the night and twilight airglow.

A general scheme of solar and terrestrial disturbance was presented by T. Obayashi (Hiraiso Radio Observatory, Japan). High-energy protons (10-100 $\mathrm{MeV}$.) reach the Earth several hours after solar flares associated with type-IV radio outbursts. These particles cause prolonged polar cap radio-blackouts in the region within geomagnetic latitudes $60-65^{\circ}$. They are followed after a day or so by the corpuscular cloud of low-energy particles travelling at a speed of the order of $1,000 \mathrm{~km}$. sec. ${ }^{-1}$. The interaction of this conducting cloud with the geomagnetic field produces the main part of geomagnetic storms. Various detailed mechanisms proposed to explain the morphology of geomagnetic disturbance and the nature of the different types of fluctuations were surveyed by
E. H. Vestine (The Rand Corp., Santa Monica, California) in a paper entitled "Problems of Geomagnetism in Relation to Aeronomy". Of great interest in this connexion are the results of rocket and satellite experiments in which many of the features theoretically inferred have actually been measured ; for example, the detection of the equatorial current in the $E$-region by Singer, Maple and Bowen, of the interplanetary fields by Sputnik III and the Soviet Moon rocket, and perhaps most exciting of all the discovery of trapped high-energy particles in the Van Allen belts. A particularly interesting finding has been the largo magnetic disturbance in interplanetary space at the time of a terrestrial magnetic storm, made by the U.S. Pioneer $V$. Field values of the order of $50 \gamma$ which were found may be compared with a general background field of $2 \gamma$ or so.

The influx of interplanetary dust, as determined by various methods, was discussed by me. There remains a gap between the smallest particles producing observable telescopic or radio meteors, and the range of particle sizes detected by rocket and satellite investigations. Satisfactory comparison between the distribution of meteor magnitudes and the distribution in particle momentum or energy as derived from rockets and satellites requires rather more detailed knowledge of the structure of the particles, their orbital distribution, and of the nature of their interaction with the atmosphere than we possess at present.

I wish to conclude by thanking, on behalf of the participants, our Danish hosts, the chairmen of the various sessions, Prof. J. Kaplan (president of the International Association of Geomagnetism and Aeronomy) and Prof. M. Nicolet (chairman of the Association's Committee on the High Atmosphere) for arranging and conducting such a stimulating and rowarding meeting. The papers contributed will shortly appear in the Annales de Géophysique and afterwards as a bound volume which, it is hoped, will be available at a price to suit the purse of individual research workers in this rapidly expanding field.

T. R. KAISER

\title{
LATTICE DEFECTS AND THE MECHANICAL PROPERTIES OF SOLIDS
}

$\mathrm{T}$ HE second symposium of the Fifth Congress of the International Union of Crystallography was held in the Guildhall at Cambridge. It opened with an introductory lecture on August 20 by Prof. N. F. Mott, who surveyed the development of our knowledge about lattice defects and their relation to mechanical properties, and outlined outstanding problems in the field. The symposium, organized by Dr. P. B. Hirsch, occupied August 22-24, and about one hundred papers were presented by contributors from eleven countries. On two days the sessions continued (with a substantial audience) until 10 p.m.; the supposedly free afternoons were, of course, usually fully occupied by private discussions. One may criticize meetings of this kind for the mental indigestion and exhaustion they produce, and argue that fuller discussion on a more restricted subject is to be preferred. Nevertheless, these larger gatherings do have a value of their own in presenting a broad picture of current progress in many associated fields, and in providing an opportunity for the assembled specialists to assess tho impact of related developments on their own particular interests.

The papers of the symposium were grouped under twelve main headings, and it is clearly not possible in the present short review to refer to the significant content of all contributions. Summaries of the papers are printed in the Congross Abstracts of Communications, and the papers will appear in full in the usual scientific journals.

Four sessions were devoted to "Yield Strength" and "Work-hardening", which are porhaps the central problems of the field. Ideas on work-hardening are still in a state of flux, and discussions took place on a number of mechanisms which may be important in determining the flow stress : the stresses due to dis. location groups (Seoger); the debris left behind by moving dislocations (Gilman, who discussed the 
velocity of dislocations as a function of stress); also, in a new theory, the associated accumulation of defects by dislocations as they move (Hirsch, Warrington and Hirseh); and the interactions arising from the intersections of dislocations with one another (Baird and Gale, Saada, Hale and McLean). The last authors, and also Howie, and Bailey and Hirsch, reported detailed correlations between observ. ations on thin films and macroscopic treatments and measurements in various metals; and flow-stress measurements were discussed by Christian, Masters, Mitchell and Pargeter, and by Basinski. Other topics treated were the theoretical strength of metals (Richards) and dislocation reactions in body-centred iron (Crussard), while considerable attention was given to the mechanical behaviour of ionic crystals (Newey and Pratt; Pratt; Silverstone and Pratt; Westwood) and of semi-conductors (Bell and Bonfield; Suzuki, Kayano and Watanabe; Bernard, Berth, Burgeat, Devaux, Mme. Soula and Tsoucaris). In the sessions on "Stacking Faults" and "Twinning", two papers were concerned with the direct measurement of stacking fault energies (Howie and Swann) and associated calculations (Bilby, Grinberg and Swinden), and a number of others described the behaviour of faults and twins as observed in thin films and under stress in the electron microscope (Phillips; Price; Fourie, Weinberg and Boswell; Catlin, Walker and Lawless; Pashley and Presland). The last authors also directed attention to fine defects ('black death') produced, probably indirectly, by the electron beam. Two papers discussed the theory of twinning (Christian; Venables) and others treated kinking in cadmium (Blasdale, King and Puttick) and in alkali halide crystals (Mme. Klassen-Nekludova), and the interplay of twinning and slip in iron (Sleeswyk) and silicon iron (Hull).

In contrast to the situation in work-hardening, the survey of probable mechanisms of "Fracture" could be given (Cottrell) without provoking instant controversy. The influence of minute surface imperfections was emphasized in papers on the Joffe effect (Stokes, Johnston and $\mathrm{Li}$ ) and on the fracture of glass (Murrell). The former authors also illustrated in another paper the interrelation of fracture and deformation in magnesium oxide. Other papers treated the fracture of zinc (Barnby and Pratt) and silicon iron (Cuff), the fracture of thin metal films (Fujiwara and Yoshida, Fisher and Nutting), and the propagation of cracks (Mme. Shaskolskaya) and the influence of inhomogeneities on this process (Bethge and Schmidt) in alkali halides. The session on "Fatigue" was opened by Thompson, and included reports on thin-film studies of the defects produced (Partridge and Segall), the role of cross-slip (Broom) and a theory of the dependence on temperature (Hirsch and Segall). Grosskreutz described experiments on crack propagation in single crystals.

There were two sessions on "Dislocations and Point Defects"- - one on "Quench Hardening" and one on "Climb and Creep". The effects of irradiation and/or cold work and the course of subsequent low-temperature recovery (usually assessed by resistivity measurements) were reported for several materials : in copper and its alloys (Pritchard and Pratt, Sosin), in molybdenum and niobium (Johnson, Peacock and Wronski) and in titanium and zirconium (Smith and Stagg). Effects of straining and ageing on the mechanical and electrical properties and the etching behaviour of alkali halides were also discussed (Slifkin, Kabler and Layer ; Curien and Mihailovic; Bethge and Fröhlich; Davidge, Whitworth and Pratt), and an extension of the general theory of strain-ageing reported (Bullough and Newman). Changes in impurity concentration around precipitates at dislocations and other sites in doped silicon were revealed directly by the formation of annular $p-n$ junctions made visible by etching (Newman, Wakefield, Willis and Bullough). Internal friction studies on cold-worked gold and copper (Hasiguti and Okuda) and on quenched aluminium (Gelli and Federighi) wore reported, as well as the influence of pressure and plastic deformation on point defects (Lazarus) and their contribution to stored energy and volume changes (Åström). Quench hardening was introduced by Maddin, and a thin-film study of the vacancy clusters produced in aluminium reported by Westmacott, Barnes, Smallman and Hull. The role of solute atoms and vacancies in the ageing of aluminium alloys was studied in thin films (Nicholson), by calorimetric and resistivity measurements (Borelius and Larsson), and by small-anglo $\mathrm{X}$-ray scattering (Gerold and Schweizer). An introductory paper on climb and creep (Friedel) was followed by a direct thin-film investigation of the shrinkage-rates of dislocation loops in zine by climb (Price). An example of the direct and subtle experiments now possible was afforded in a paper by Dash, who was able to a rgue that climb observed in silicon due to the introduction of gold was due to vacancy deficiency, since left-hand screw dislocations formed right-hand helices. In similar vein, Barnes and Mazey showed. that certain dislocation loops in copper foils induced by $\alpha$-particles were formed by condensed interstitials, since in a foil where the particles come to rest the loops grow during the precipitation of helium bubbles, which is a process requiring vacaneies. Other papers in the two sessions on "Radiation Damage" included work on copper and other face-centred cubic metals (Blewitt, Coltman, Jamison and Redman; Silcox; Makin, Whapham and Minter; Seeger, Mader and Essmann), on graphite (Williamson and Baker ; Fujita and Izui) and on fission in uranium steel (Baker and Nutting). A general discussion of dislocation-point defect interaction was given by Sosin.

The session on "Recrystallization" and related phenomena included thin-film investigations on silver (Bailey) and work with other techniques on a titanium molybdonum alloy (Schofield and Bacon) and on aluminium (Weissmann, Imura and Nakayama; Fujiwara and Takano). Grain-boundary motion in sintering was discussed by Horustra and van Bueren. In the session on "Alloy Hardening". A. Kelly reviewed the yield strength of alloys, and thin-film observations on the dislocations in ordered alloys were discussed in two papers (Pashley and Presland ; Marcinkowsky, Brown and Fisher). Work was also reported on the order and precipitation hardening in a nickel ( 24 per cent), chromium (15) per cent), aluminium ( 3.5 per cont) austenitic steel (Blackburn and Nutting), and of dislocations and precipitates in an austenitic steel containing niobium (Arrowsmith and Nutting).

The final session, on "Martensitic Transformations", was introduced by Read, who also discussed the plasticity of metals undergoing polymorphic transformation. Again, important work using the thinfilm technique is revealing hore the fine details of the transformation process. P. M. Kolly reported thinfilm work on high- and low-carbon steels and on 
iron-nickel alloys, and suggested correlations between the twinning and different morphologies observed and the martensite hardness. Venables has worked on thin films of stainless steel transformed by cold work, where stacking faults, regions of hexagonal $\varepsilon$-phase and regions of body-centred cubic $\alpha^{\prime}$-phase can be seen. Other papers in this session described exten. sions to the crystallographic theory (Wechsler and Otte) and etch-pit investigations of dislocations in the austenite (Reed and Greeson).

Thus, the subject of defects in crystals continues to expand at an ever-increasing rate, particularly under the stimulus of the development of experi mental techniques permitting direct observation of dislocation lines, of which the dominant one is now the use of the electron microscope to examine thin metal films by transmission. With these highresolution studies, our knowledge of the detailed behaviour of individual dislocations and other lattice defects is increasing rapidly, and the next ten years will see a great extension in work of this kind. While possible differences in the behaviour of defects in thin films and bulk specimens must always be borne in mind, it is clear that much valuable information about the basic mechanisms controlling bulk mechanical properties will be obtained in this way. Such information must indeed play an essential part in the solution of the more difficult problems concerned with the development of theories about the bulk mechanical properties of practical interest.
B. A. BாLBY

\section{CO-ORDINATION CHEMISTRY}

A SYMPOSIUM on Co-ordination Chemistry with an international attendance was held in Prague during September 5-8. It was organized by the Czechoslovak Chemical Society and by the Faculties of Inorganic Chemistry of the Charles University and the Technical University and sponsored by the C.zechoslovak Academy of Sciences.

The introductory paper by Prof. A. A. Grinberg (Leningrad) consisted of a survey of the development of co-ordination chemistry in the past decade and a general review of the present position of the subject. This was followed by a general discussion of the applications of polarography by Dr. A. A. Vlček, a member of the Polarographic Institute at Prague. Dr. Vleek emphasized, in particular, the importance of searching for new complexing agents which would permit the electro-deposition of a wider range of metals than can at present be utilized in this way.

The other scientific meetings were grouped into three sections, concerned with modern preparative methods, with the physico-chemical properties and structure of complexes, and with direct methods of structure determination, respectively. Prof. S. Herzog opened the first main session with a paper on the properties of low-valency co-ordination compounds of metals with dipyridyl and phenanthroline. $\mathrm{He}$ described some remarkable substances, for example, zero-valent tris-dipyridyl derivatives of titanium, scandium and even niobium. The existence of such compounds and of magnesium and lithium dipyridyl derivatives was shown to raise a number of important problems in valency theory which were discussed in some detail. Whother these compounds are to be regarded as truo low-valency compounds of the metals, or as complexes of the dipyridyl anion radical, was the interesting question which emerged in discussion.

Among the contributed papers one can mention only a few. Prof. E. O. Fischer (Munich) described the preparation of a variety of mixed diene-carbonyl complexes of zero-valent metals and discussed some very remarkable rearrangements which they undergo. Prof. I. I. Chernaev (Moscow) described his extensive work on the nitro complexes of tetravalent platinum. Dr. K. Isslieb (Jena) described a large number of novel complexes of transition-metal ions with primary and secondary phosphines. Complexes of tri- and tetra-dentate arsenic ligands were discussed by a group from Oxford.
The section on physico-chemical methods was opened by Dr. L. E. Orgel (Cambridge), who gave an elementary account of the principles of ligand-field theory and of modern methods of determining the spatial distribution of unpaired $d$ electrons in transition-metal complexes. This was followed by an entertaining paper by Dr. L. G. Sillen (Stockholm). who summarized the extensive research of his school on the varied hydrolysis reactions of metal ions in equeous solution.

Madame B. Jezowska-Trzebiatowska (Warsaw) described the use of optical and magnetic measurements in discussing the electronic structure of a variety of co-ordination complexes. The trans effect in a variety of complexes of divalent platinum, trivalent cobalt and divalent copper was treated in a series of papers.

A further group of papers dealt with applications of polarographic methods. Prof. K. B. Yatsimirskii (Kiev) described ingenious methods of using the catalytic polarographic currents to study complexes in solution; Miss D. Wagnerova (Prague) discussed the polarographic reduction of ruthenium nitrosyls, and Dr. E. Fischerova described similar work on trivalent chromium complexes.

The final section was opened by Prof. Porai Koshitz (Moscow), who gave a concise summary of the present state of our knowledge of the environments of metal ions in co-ordination compounds as determined by direct $\mathrm{X}$-ray studies. There followed a series of papers describing structural studies on individual compounds. One may mention in par. ticular papers on the periodate of trivalent copper, on the dipyridine adduct of the dimer of copper acetate, and on $\left(\mathrm{NH}_{2} \cdot \mathrm{CH}_{2} \cdot \mathrm{CH}_{2} \cdot \mathrm{NH}_{2}\right) \mathrm{CuBr}_{2}$. Another paper in this series by Czech crystallographers discussed the mechanism of the substitution reactions of cupric compounds.

The meeting as a whole provided an excellent opportunity for the exchange of ideas and information between scientists of all countries. For those from the Western countries it was a particular pleasure to meet and talk with their opposite numbers from Eastern Europe. Apart from tho main soientific business of the meeting, foreign delegates were most hospitably entertained-a tour of the medieval city of Prague, an excursion to neighbouring points of interest and the various social activities in the evenings were greatly enjoyed by those present. L. F. OraEL 